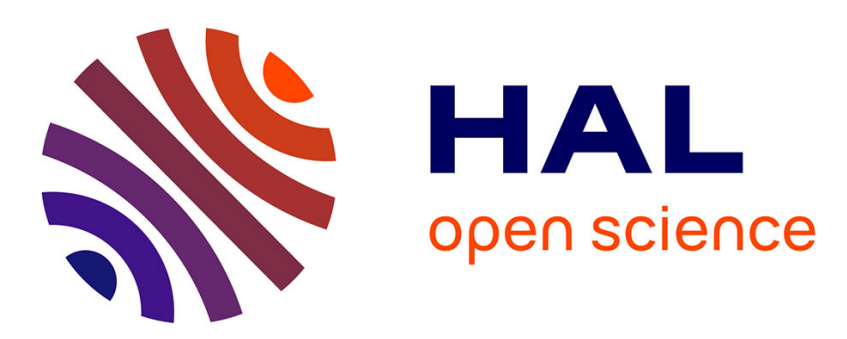

\title{
Epoxy composites with ceramic core-shell fillers for thermal management in electrical devices
}

Andrzej Rybak, Karolina Gaska, Czeslaw Kapusta, Francois Toche, Vincent Salles

\section{- To cite this version:}

Andrzej Rybak, Karolina Gaska, Czeslaw Kapusta, Francois Toche, Vincent Salles. Epoxy composites with ceramic core-shell fillers for thermal management in electrical devices. Polymers for Advanced Technologies, 2017, 28 (12), pp.1676-1682. 10.1002/pat.4038 . hal-02556223

\section{HAL Id: hal-02556223 https://hal.science/hal-02556223}

Submitted on 27 Apr 2021

HAL is a multi-disciplinary open access archive for the deposit and dissemination of scientific research documents, whether they are published or not. The documents may come from teaching and research institutions in France or abroad, or from public or private research centers.
L'archive ouverte pluridisciplinaire $\mathbf{H A L}$, est destinée au dépôt et à la diffusion de documents scientifiques de niveau recherche, publiés ou non, émanant des établissements d'enseignement et de recherche français ou étrangers, des laboratoires publics ou privés. 


\title{
Epoxy composites with ceramic core-shell fillers for thermal management in electrical devices
}

\author{
Andrzej Rybak ${ }^{1 *}$, Karolina Gaska $^{2}$, Czeslaw Kapusta $^{2}$, François Toche $^{3}$, Vincent Salles ${ }^{3}$
}

\author{
${ }^{1}$ ABB Corporate Research Center, Starowislna 13A, 31-038 Kraków, Poland \\ *andrzej.rybak@pl.abb.com, Phone: +48 22223 8488, Fax: +48 222239501 \\ ${ }^{2}$ AGH University of Science and Technology, Faculty of Physics and Applied Computer \\ Science, Department of Solid State Physics, Mickiewicza 30, 30-059 Kraków, Poland \\ ${ }^{3}$ Laboratoire des Multimatériaux et Interfaces, UMR 5615 CNRS - Université Lyon 1, \\ Université de Lyon, 43 bd du 11 Novembre 1918, 69622 Villeurbanne Cedex, France
}

\begin{abstract}
In this work a novel core-shell material has been manufactured in order to enhance the thermal conductivity of epoxy based composites. The polymer derived ceramics technique has been used to produce fillers whose core is composed of a standard material - silica, and whose outer layer consists of a boron nitride or silicon nitride shell. The synthesized filler was characterized by infrared spectroscopy, X-ray diffraction, and scanning electron microscopy coupled with an energy dispersive spectroscopy analysis. The successful formation of core-shell structure was proven. Composite samples based on an epoxy resin filled with 31 vol.\% of synthetized core-shell filler have been investigated in order to determine the effective thermal conductivity of the modified system. The resulting core-shell composite samples exhibited improvements in thermal conductivity of almost $30 \%$ in relation to standard systems, making them a promising material for heat management applications. Additionally the temperature dependence of the thermal conductivity was investigated over a broad temperature range indicating that the thermal behavior of the composite with
\end{abstract}


incorporated core-shell filler is stable. This stability is a crucial factor when considering the potential of using this technology in applications such as electronics and power systems.

Keywords: functional composite, core-shell filler, thermal management, thermal conductivity

\section{Introduction}

Filled epoxy resins are well known and extensively used as insulating materials in power product applications. The addition of filler particles into epoxy resin can result in a significant improvement in the thermal, electrical or mechanical properties of the obtained composite [1-5]. The management of heat dissipation is a crucial consideration when ensuring the proper operation of such devices, with improper heat management potentially leading to malfunctions [6-8]. Optimized thermal management in electronic components, can lead either to reducing of the footprint or allowing a component to be rated for greater power ranges.

Besides the matrix thermal conductivity, the thermal properties of a composite are also related to the kind of filler used, the grain size, the content of this filler and its alignment in the matrix $[1-4,9-12]$. The quality of the filler-epoxy matrix interface seems to be crucial in ensuring the precise control of the thermal properties of a composite $[13,14]$. In particular, it is necessary to consider the strong phonon scattering processes as well as the interface resistance $[2,15,16]$. To increase thermal conductivity in epoxy composite materials, conductive paths must be maximized and thermal contact resistances must be reduced. A promising approach for creating composites that fulfil these requirements involves the modification of filler particles $[17,18]$.

The heat dissipation properties of thermally conducting composites has been the subject of numerous theoretical and experimental studies [2-4,14]. Composites filled with high thermal 
conductivity materials have been shown to offer huge potential as a thermally conducting material. Whilst the composites offer significant improvements in effective thermal conductivity, there are also some disadvantages associated with using the material. First of all, fillers with very high thermal conductivity (HTC) are usually expensive, resulting in their application being questionable from an economical point of view, especially when high filler contents are required. On the other hand, less expensive fillers are not suitable for significant enhancement of thermal conductivity. A second disadvantage relates to the electrical insulation function of the composite. Requirements that a composite should maintain electrical insulation limits the variation in fillers that may be used, with ceramic particles with good dielectric properties being the most appropriate. Therefore, from an application point of view it is necessary to strike a compromise between the overall cost of composite and the type of filler necessary in order to obtain a suitable thermal conductivity for the whole system. A potential solution to these conflicting requirements is to create a core-shell like structure, whose core is composed of cheap standard material and covered with a low amount of expensive HTC shell [19]. Several examples of different core-shell particles have been previously described [20-23]. Recently, the authors have demonstrated a successful approach with a fully ceramic core-shell fillers synthesis by means of carbothermal reduction and nitridation process which were incorporated into epoxy matrix in order to create electrical insulation with enhanced thermal conductivity [24].

In this work a polymer derived ceramics (PDCs) technique has been applied in order to produce a filler whose core is composed of silica flour, covered by boron nitride and silicon nitride shell. The PDCs is a known synthesis method for creating advanced ceramic materials [25-29].

The aim of the present work is to use a core-shell filler structure, with the core made of a standard and cheap material such as $\mathrm{SiO}_{2}$, and the coating made of a high-thermalconductivity (HTC) material, namely boron nitride $(\mathrm{BN})$ or silicon nitride $\left(\mathrm{Si}_{3} \mathrm{~N}_{4}\right)$ in order to 
increase the thermal conductivity of the filled epoxy resin systems. The addition of the modified filler can significantly increase the effective thermal conductivity of composite. The core-shell filler materials obtained were investigated using infrared (IR), X-ray diffraction (XRD), X-ray photoelectron spectroscopy (XPS), and also characterized by scanning electron microscopy (SEM) coupled with energy dispersive X-ray spectroscopy (EDS). A representative set of epoxy matrix samples filled with core-shell material has been prepared and compared with the reference samples. Thermal conductivity measurements have been performed on these samples at room temperature and also as a function of temperature over a wide range from $10 \mathrm{~K}$ to $400 \mathrm{~K}$.

\section{Experimental}

\subsection{Core-shell filler preparation}

The first type of filler was prepared to form silicon nitride-coated silica, referred hereafter as $\mathrm{SiO}_{2} @ \mathrm{Si}_{3} \mathrm{~N}_{4}$. A volume of $40 \mathrm{~mL}$ of Perhydropolysilazane (PHPS, Sigma Aldrich), used as a silicon source, was poured into a beaker under ambient conditions. A folded filter containing $0.66 \mathrm{~g}$ of silica flour (Millisil W12, delivered by Quarzwerke) was consecutively dived into the solution during 15 minutes. The filter was then removed from the solution and unfolded in order to allow the powder to dry. The coated powder was left inside the unfolded filter at room temperature overnight under a hood.

After drying, the $\mathrm{Si}_{3} \mathrm{~N}_{4}$-coated powders were transferred to an alumina crucible before a thermal treatment was applied at $1000^{\circ} \mathrm{C}$ with a rate of $5^{\circ} \mathrm{C} / \mathrm{min}$ and a plateau of $2 \mathrm{~h}$ under a flowing nitrogen atmosphere. A part of this powder was then heat-treated at $1400^{\circ} \mathrm{C}$ in order to obtain a crystallized nitride phase. A simplified scheme of the synthesis process is shown in Fig. 1 (upper part).

A second kind of filler was prepared to form a boron nitride coated silica (referred as $\left.\mathrm{SiO}_{2} @ \mathrm{BN}\right)$. Silica particles were coated with a layer of boron nitride $(\mathrm{BN})$ starting from boric 
acid $\left(\mathrm{H}_{3} \mathrm{BO}_{3}\right)$ as a boron source. In a typical experiment, $200 \mathrm{~mL}$ of a $1 \mathrm{M}$ solution of boric acid in methanol was prepared at room temperature, before the addition of $0.61 \mathrm{~g}$ of silica flour powders. The mixture was then stirred for 10 minutes before being kept for 5 days at room temperature under a hood until the methanol had totally evaporated. The dry powder was then heated in an alumina crucible to $1000^{\circ} \mathrm{C}$ at a rate of $10^{\circ} \mathrm{C} / \mathrm{min}$ and held for $2 \mathrm{~h}$ under a flowing ammonia atmosphere. The flow was finally replaced by a nitrogen one during the cooling step (cf. middle part of scheme shown in Fig. 1).

\subsection{Composites preparation and thermal conductivity measurement technique.}

An epoxy derived from bisphenol A (DGEBA) CY 228-1 which had been hardened with HY918 (derived by Huntsman) was selected as a standard system used for impregnation and casting of the power products. Composite samples were prepared by mixing the epoxy resin system with a filler content of 31 vol.\%. Such a volume fraction was selected as typically used in the electrical insulation systems. A conventional vacuum casting method utilizing a typical curing profile found in the producer data sheet was used during the preparation of the samples (see bottom part of Fig. 1).

The thermal conductivity of the material was investigated using the pulse-power method of the thermal transport option of the Physical Property Measurement System (PPMS) equipment (Quantum Design). Small cylindrical samples with a diameter of $6 \mathrm{~mm}$ and a height in the range of 3 to $6 \mathrm{~mm}$ were cut from the material and tested. Measurements were carried out at room temperature for three samples of each composite, and the average values are presented. Heat pulses were injected into the test samples by a heater which was connected to a copper electrode that had been adhered to the sample surface. The thermal conductivity was measured under high vacuum $\left(10^{-6}\right.$ Torr $)$ in a steady-state at room temperature, but also as a function of temperature, starting from cryogenic temperatures, specifically $2 \mathrm{~K}[4,30]$. 


\section{Results and discussion}

\subsection{Characterization of powders}

\subsubsection{Infrared spectroscopy}

The obtained $\mathrm{BN}$ and PHPS coated $\mathrm{SiO}_{2}$ powder was investigated by Fourier Transform Infrared spectroscopy (Attenuated Total Reflectance FTIR Nicolet 380, Thermo Scientific), in order to find the bonding character of boron and nitrogen with the silica particles.

The mid-infrared (MIR) spectra of pure and $\mathrm{BN}$ coated $\mathrm{SiO}_{2}$ are shown in Fig. 2 (bottom and middle spectra). The positions and intensities of predominant bands in both cases are almost the same and are related to stretching vibration of $\mathrm{Si}-\mathrm{O}\left(950-1200 \mathrm{~cm}^{-1}\right)$ and silicon oxide bending modes (below $600 \mathrm{~cm}^{-1}$ ) [31-34]. However, a clear difference between the these two spectra is observed at $1380 \mathrm{~cm}^{-1}$ (broad band), where BN absorption is expected. Indeed, pure BN has two characteristic bands: a strong band at $1373 \mathrm{~cm}^{-1}$ attributed to B-N stretching vibrations and a weaker band at $816 \mathrm{~cm}^{-1}$ attributed to B-N-B bending vibrations [34].

In the case of MIR spectra for PHPS-coated silica before heat treatment (c.f. top spectrum in Fig. 2), the positions and intensities of $\mathrm{SiO}_{2}$ bands for pure and coated silica are almost the same, but a difference shift is observed in the range $850-1000 \mathrm{~cm}^{-1}$, where the strongest $\mathrm{Si}-\mathrm{N}$ absorption bands are expected, with a $\mathrm{Si}-\mathrm{N}-\mathrm{Si}$ asymmetric stretching given at different values and ranges depending on the authors $\left(925 \mathrm{~cm}^{-1}\right.$ [35], 800-1000 $\mathrm{cm}^{-1}[36], 840-1020 \mathrm{~cm}^{-1}$ [37] . This shift can indicate that the sample contains PHPS before the furnace treatment.

\subsubsection{Electron microscopy imaging}

A scanning electron microscope (SEM, Hitachi S800) equipped with energy-dispersive spectroscopy analysis (EDS) was used to analyze the coated particles. Comparing the EDS measurements of the pure $\mathrm{SiO}_{2}$ powders with equivalent measurements of the material obtained after BN deposition, (see Fig. 3) clearly shows the presence of BN in the batch, as evidenced by the two peaks around 0.2 and $0.4 \mathrm{keV}$. 
The SEM picture of SiO2@BN (see middle image in Fig. 4) seems to indicate agglomerates which probably appear due to a high content of $\mathrm{BN}$ since the $\mathrm{B} / \mathrm{Si}$ molar ratio was fixed at 20 in our process.

The right image in Fig. 4 presents a SEM picture of $\mathrm{SiO}_{2} @ \mathrm{Si}_{3} \mathrm{~N}_{4}$ powders after treatment at $1000^{\circ} \mathrm{C}$. One can distinguish a film on the powder surface which could correspond to the $\mathrm{Si}_{3} \mathrm{~N}_{4}$ deposition already detected using FTIR technique. The particle size measured here is similar to that of the raw powder (see left image in Fig. 4) confirming there is no significant modification of the particle size after the formation of nitride layer.

\subsubsection{X-ray photoelectron spectroscopy (XPS)}

X-ray photoelectron spectroscopy (XPS) experiments were carried out on both batches: $\mathrm{SiO}_{2} @ \mathrm{BN}$ and $\mathrm{SiO}_{2} @ \mathrm{Si}_{3} \mathrm{~N}_{4}$. In both cases a nitrogen element was detected, as well as boron for the boron containing powder. The obtained values after quantification are presented in Table 1, with a higher content of nitrogen for the $\mathrm{BN}$-containing batch, meaning that the $\mathrm{BN}$ film seems to be thicker than the $\mathrm{Si}_{3} \mathrm{~N}_{4}$ one. The presence of carbon is due to the carbon tape on which the powders where deposited for SEM observations. These measurements were performed after grinding of the as-pyrolysed powders, implying that a part of the silicon detected could correspond to the silica. Moreover the coating is certainly not thick enough to prevent the electron beam from reaching the silica grains. This explains why, for instance, a high content of $\mathrm{Si}$ was detected in the BN-coated material.

\subsubsection{X-ray diffraction}

The core-shell powders were investigated by X-ray diffraction (PANalytical MPD). Boron nitride remains amorphous at temperatures lower than $1400^{\circ} \mathrm{C}$. Therefore a trial was conducted where the temperature of a part of the $\mathrm{SiO}_{2} @ \mathrm{BN}$ sample was increased up to $1400^{\circ} \mathrm{C}$. However the XRD results highlighted only the formation of Crystoballite instead of 
a Quartz phase for $\mathrm{SiO}_{2}$. The main $\mathrm{BN}$ crystalline phase peak (around $2 \theta=26.7^{\circ}$ ) was still absent.

The XRD patterns of as-received $\mathrm{SiO}_{2}$ and treated $\mathrm{SiO}_{2}$ are compared in Fig. 5. The crystalline phase of $\mathrm{SiO}_{2}$ was pure Quartz. This phase was also observed in the sample after treatment $1400^{\circ} \mathrm{C}$, but a second phase of $\mathrm{SiO}_{2}$ (Cristobalite) was formed during the treatment. The diffraction peak at positions $13^{\circ} 2 \Theta$ and shoulder (at $31^{\circ} 2 \Theta$ ) could be attributed to $\mathrm{Si}_{3} \mathrm{~N}_{4}$. From the $\mathrm{XRD}$ patterns obtained after intermediate treatment at $1000^{\circ} \mathrm{C}$, it may be observed that that the signal relating to Cristobalite is absent. This is consistent with the fact that silicon nitride crystallizes more rapidly above $1200^{\circ} \mathrm{C}$. It must be noted that the hightemperature treatment was performed in order to highlight the formation of crystalline $\mathrm{Si}_{3} \mathrm{~N}_{4}$ but, obviously, this sample was subjected to a pyrolysis up to $1000^{\circ} \mathrm{C}$ in order to prevent the Quartz-to-Cristobalite transformation.

\subsubsection{EDS analysis}

The obtained powders were characterized by means of SEM coupled with EDS analysis. The modified core-shell grains have been dispersed in the epoxy resin and were polished with sub-micron diamond pastes what allowed the cross-section of each sample to be observed. Several grains were analyzed precisely in order to check reproducibility of the layer formation. Fig. 6 shows an example of SEM image of a grain cross-section of the $\mathrm{SiO}_{2} @ \mathrm{BN}$ sample.

Elemental analysis was conducted for each of the selected points as indicated in Fig. 6: points from 1 to 4 are placed on the edge of the grain, whereas point 5 is located in the center of the grain. Table 2 shows detailed results of EDS point analysis. It is clearly seen that content of boron and nitrogen is significantly increased at the outer layer of the grain which correlates well with the XPS results and confirms that the BN layer was synthesized successfully. In 
order to estimate the thickness of the BN coating, EDS linear analysis was performed on several grains. An example of such analysis is shown in Fig. 7.

After analysis of several EDS spectra it can be concluded that the layer of BN created on $\mathrm{SiO}_{2}$ grain is not uniform, however the thickness is in the following range $0.8-3.0 \mu \mathrm{m}$. Such a thickness should be sufficient to increase the effective thermal conductivity of the core-shell grain.

In the case of the $\mathrm{SiO}_{2}$ grains coated with $\mathrm{Si}_{3} \mathrm{~N}_{4}$ it was hard to detect the coating. This observation is in good agreement with XPS data where the signal corresponding to $\mathrm{Si}_{3} \mathrm{~N}_{4}$ was much weaker than the equivalent for $\mathrm{BN}$. Therefore one can conclude that layer of $\mathrm{Si}_{3} \mathrm{~N}_{4}$ created on $\mathrm{SiO}_{2}$ is extremely thin.

\subsection{Thermal conductivity results for composites}

Thermal conductivity values measured for the prepared composites with incorporated coreshell fillers are presented in Table 3 . The effective thermal conductivity was enhanced by $8 \%$ in case of $\mathrm{SiO}_{2} @ \mathrm{BN}$, whereas in the case of $\mathrm{SiO}_{2} @ \mathrm{Si}_{3} \mathrm{~N}_{4}$ the observed thermal conductivity was significantly increased by $27 \%$ in relation to the reference sample. It is worth noting that although a much thinner layer of HTC coating is present, namely silicon nitride in the case of $\mathrm{SiO}_{2} @ \mathrm{Si}_{3} \mathrm{~N}_{4}$ powder, the observed thermal conductivity is more enhanced (increased by three times) in comparison to $\mathrm{SiO}_{2} @ \mathrm{BN}$ filler for which a thicker $\mathrm{HTC}$ coating, namely boron nitride, was obtained. The XRD results showed that crystallinity is poor for both the BN and $\mathrm{Si}_{3} \mathrm{~N}_{4}$ coatings, however a slightly better crystalline degree was observed for the silicon nitride shell. Therefore a higher enhancement of thermal conductivity can be expected in the case of $\mathrm{SiO}_{2} @ \mathrm{Si}_{3} \mathrm{~N}_{4}$ due to the hindered scattering of phonons during heat transport. The observed results indicate that there is still place for optimization of the proposed core-shell filler structure, e.g. control of HTC layer thickness, its crystallinity and homogeneity. 
Taking into consideration the results reported in literature for core-shell filler based polymer composites with similar filler content (40 wt.\% for literature results vs. 50 wt. $\%$ in our case), e.g. alumina-coated graphene sheet $\left(\mathrm{GS} @ \mathrm{Al}_{2} \mathrm{O}_{3}\right)$ or reduced graphene oxide-encapsulated $\mathrm{SiO}_{2}\left(\mathrm{SiO}_{2} @ \mathrm{RGO}\right)[21,22]$, the obtained values $(0.57$ and $0.45 \mathrm{~W} / \mathrm{mK}$, respectively) are comparable or even lower to those which were obtained in our study (see Table 3 ). On the other hand, one can find example of composites with incorporated core-shell structure giving better results, e.g. silica coated silver $\left(\mathrm{Ag} @ \mathrm{SiO}_{2}\right)$ nanoparticles [20], however the fraction of filler was much higher than in our case (50 vs. 31 vol.\%), what is an aspect which could have a strong influence on the results. It might be also hard to justify the use of noble metal nanostructures for industrial applications due to problems associated with volume production and the handling of nanoparticles.

An additional experiment, namely the temperature dependence of the thermal conductivity, was also conducted, with the results being presented in Fig. 8. One can observe that the effective thermal conductivity of composites is stable over a wide range of temperatures from $300 \mathrm{~K}$ to $150 \mathrm{~K}$. This makes the composites filled with the modified core-shell filler very promising from the application point of view, because stable thermal conductivity is necessary for the correct operation of electrical devices.

The schematic representation of the heat transport mechanism is shown in the right part of Fig. 8. The HTC shell material is mainly responsible for effective heat dissipation and enhancement of the overall thermal conductivity of the composite.

\section{Conclusions}

The performed research work has demonstrated that a new type of core-shell fillers can be prepared by means of the polymer derived ceramics synthesis method. On the basis of the obtained characterization results for the modified particles it was confirmed that the coreshell structure formation was successful. It was shown that the application of the core-shell 
fillers, especially silica with silicon nitride shell $\left(\mathrm{SiO}_{2} @ \mathrm{Si}_{3} \mathrm{~N}_{4}\right)$, has resulted in an improvement of the effective thermal conductivity of the filled epoxy composite. The enhanced thermal conductivity (up to $27 \%$ ) of the system with incorporated novel core-shell filler can open the way for more affordable epoxy composites suitable for application as an advanced material for the thermal management in electrical devices.

\section{Acknowledgements}

The authors gratefully acknowledge the support from James Ottewill for correcting English language.

\section{References}

[1] G. Droval, J.F. Feller, P. Salagnac, P. Glouannec, Polym. Adv. Technol. 2006; 17, 732.

[2] K.W. Garrett, H.M. Rosenberg, J. Phys. Appl. Phys. 1974; 7, 1247.

[3] K. Gaska, A. Rybak, C. Kapusta, R. Sekula, A. Siwek, Polym. Adv. Technol. 2015; $26,26$.

[4] K. Gaska, G. Kmita, A. Rybak, R. Sekula, K. Goc, C. Kapusta, J. Mater. Sci. 2015; $50,2510$.

[5] M. Donnay, S. Tzavalas, E. Logakis, Compos. Sci. Technol. 2015; 110, 152.

[6] M.P. Filippakou, C.G. Karagiannopoulos, D.P. Agoris, P.D. Bourkas, Electr. Power Syst. Res. 2001, 57, 141.

[7] C.P. Wong, R.S. Bollampally, J. Appl. Polym. Sci. 1999; 74, 3396.

[8] S. Yu, J. W. Lee, T. H. Han, C. Park, Y. Kwon, S. M. Hong, C. M. Koo, ACS Appl. Mater. Inter. 2013; 5, 11618. 
[9] H. Yan, Y. Tang, W. Long, Y. Li, J. Mater. Sci. 2014; 49, 5256.

[10] D. K. Smith, M. L. Pantoya, Compos. Sci. Technol. 2015; 118, 251.

[11] C. Yuan, B. Duan, L. Li, B. Xie, M. Huang, X. Luo, ACS Appl. Mater. Inter. 2015; 7, 13000.

[12] K. Kim, H. Ju, J. Kim, Compos. Sci. Technol. 2016; 123, 99.

[13] B. Lee, G. Dai, J. Mater. Sci. 2009; 44, 4848.

[14] A. K. Roy, B. L. Farmer, V. Varshney, S. Sihn, J. Lee, S. Ganguli, ACS Appl. Mater. Inter. 2012; 4, 545.

[15] R. Berman, Cryogenics 1965; 5, 297.

[16] J. Huang, M. Gao, T. Pan, Y. Zhang, Y. Lin, Compos. Sci. Technol. 2014; 95, 16.

[17] R. Pal, Mater. Sci. Eng. A 2008; 498, 135.

[18] D.S. Muratov, D.V. Kuznetsov, I.A. Il'inykh, I.N. Burmistrov, I.N. Mazov, Compos. Sci. Technol. 2015; 111, 40.

[19] A. Michalik, G. Kmita, T. Kazmierczak, R. Sekula, An insulating composite material with a polymer matrix, 2011; Patent nr WO2011057782.

[20] Y. Zhou, L. Wang, H. Zhang, Y. Bai, Y. Niu, H. Wang, Appl. Phys. Lett. 2012; 101, 012903.

[21] R. Qian, J. Yu, C. Wu, X. Zhai, P. Jiang, RSC Adv. 2013; 3, 17373.

[22] L. Huang, P. Zhu, G. Li, D. Lu, R. Sun, C. Wonged, J. Mater. Chem. A 2014; 2, 18246.

[23] S. Yu, B. I. Park, C. Park, S. M. Hong, T. H. Han, C. M. Koo, ACS Appl. Mater. Inter. 2014; 6,7498 .

[24] A. Rybak, K. Gaska, J. Mater. Sci. 2015; 50, 7779. 
[25] M. Peuckert, T. Vaahs, M. Bruck, Adv. Mater. 1990; 2, 398.

[26] J. Bill, F. Aldinger, Adv. Mater. 1995; 7, 775.

[27] S. Duperrier, C. Gervais, S. Bernard, D. Cornu, F. Babonneau, P. Miele, J. Mater. Chem. 2006; 16, 3126.

[28] V. Salles, S. Bernard, J. Li, A. Brioude, S. Chehaidi, S. Foucaud, P. Miele, Chem. Mater. 2009; 21, 2920.

[29] V. Salles, S. Bernard, A. Brioude, D. Cornu, P. Miele, Nanoscale 2010; 2, 215.

[30] O. Maldonado, Cryogenics 1992; 32, 908.

[31] M. Sitarz, C. Czosnek, P. Jelen, M. Odziomek, Z. Olejniczak, M. Kozanecki, J. F. Janik, Spectrochim. Acta A 2013, 112, 440.

[32] M. A. Karakassides, D. Gournis and D. Petridis, Clay Minerals 1999, 34, 429.

[33] M. Sitarz, J. Non Cryst. Solids 2011, 357, 1603.

[34] M. Sitarz, W. Jastrzębski, P. Jeleń, E. Długoń, M. Gawęda, Spectrochim. Acta A 2014, 132, 884 .

[35] G. E. Yu, M. J. Edirisinghe, D. S. Finch, B. Ralph, J. Parrick, J. Eur. Ceram. Soc. $1995,15,581$.

[36] O. Funayama, T. Kato, Y. Tashiro, T. Isoda, J. Am. Ceram. Soc. 1993, 76, 717.

[37] Y. Iwamoto, K. I. Kikuta, S. I. Hirano, J. Mater. Res. 1998, 13, 353. 
Tables:

Table 1. Composition determined during XPS analysis.

\begin{tabular}{cccccc}
\hline Content (wt.\%) & $\mathrm{B}$ & $\mathrm{N}$ & $\mathrm{C}$ & $\mathrm{O}$ & $\mathrm{Si}$ \\
& & & & & \\
\hline $\mathrm{SiO}_{2} @ \mathrm{BN}$ & 34,3 & 33,9 & 13,4 & 15,2 & 3,3 \\
\hline $\mathrm{SiO}_{2} @ \mathrm{Si}_{3} \mathrm{~N}_{4}$ & 0,0 & 5,2 & 9,7 & 56,3 & 28,8 \\
\hline
\end{tabular}

Table 2. Results of EDS point analysis of cross-section of $\mathrm{SiO}_{2} @ \mathrm{BN}$ grain. Points correspond to places indicated in Fig. 7.

\begin{tabular}{ccc}
\hline Point & B (wt. \%) & N (wt.\%) \\
\hline 1 & 21.40 & 8.69 \\
2 & 20.40 & 5.80 \\
3 & 17.71 & 13.06 \\
4 & 20.11 & 11.79 \\
5 & 8.39 & 1.57 \\
\hline
\end{tabular}

Table 3. Thermal conductivity results obtained at 300K, for composites filled (31 vol.\%) with designed fillers $\mathrm{SiO}_{2} @ \mathrm{BN}$ and $\mathrm{SiO}_{2} @ \mathrm{Si}_{3} \mathrm{~N}_{4}$.

\begin{tabular}{ccc}
\hline Sample & $\kappa(\mathrm{W} / \mathrm{mK})$ & Relative increase \\
& at $300 \mathrm{~K}$ & $(\%)$ \\
\hline $\mathrm{SiO}_{2}$ & 0.62 & - \\
\hline $\mathrm{SiO}_{2} @ \mathrm{BN}$ & 0.67 & 8 \\
\hline $\mathrm{SiO}_{2} @ \mathrm{Si}_{3} \mathrm{~N}_{4}$ & 0.79 & 27 \\
\hline
\end{tabular}




\section{Figure captions:}

Figure 1. Schematic representation of core-shell filler synthesis steps: $\mathrm{SiO}_{2} @ \mathrm{Si}_{3} \mathrm{~N}_{4}$ (top scheme), $\mathrm{SiO}_{2} @ \mathrm{BN}$ (middle scheme), and composite samples preparation procedure (bottom scheme).

Figure 2. MIR spectra of reference $\mathrm{SiO}_{2}, \mathrm{BN}$ coated $\mathrm{SiO}_{2}\left(\mathrm{SiO}_{2} @ \mathrm{BN}\right)$, and PHPS-coated $\mathrm{SiO}_{2}\left(\mathrm{SiO}_{2} @ \mathrm{Si}_{3} \mathrm{~N}_{4}\right)$.

Figure 3. Results of the EDS measurements for pure $\mathrm{SiO}_{2}$ and $\mathrm{SiO} 2 @ \mathrm{BN}$ powders.

Figure 4. $\mathrm{SEM}$ image of raw $\mathrm{SiO}_{2}$ (left), $\mathrm{SiO}_{2} @ \mathrm{BN}$ (middle) and $\mathrm{SiO}_{2} @ \mathrm{Si}_{3} \mathrm{~N}_{4}$ (right) powders after treatment at $1000^{\circ} \mathrm{C}$

Figure 5. XRD patterns of $\mathrm{SiO}_{2}$ as-received (top graph) and modified $\mathrm{SiO}_{2} @ \mathrm{Si}_{3} \mathrm{~N}_{4}$ particles annealed at $1000^{\circ} \mathrm{C}$ and $1400^{\circ} \mathrm{C}$.

Figure 6. SEM image of cross-section of $\mathrm{SiO}_{2} @ \mathrm{BN}$ grain. White numbers indicate the location of each EDS point analysis.

Figure 7. SEM image of cross-section of $\mathrm{SiO}_{2} @ \mathrm{BN}$ grains (top image). The white line indicates the axis along which the EDS analysis was performed. Results of EDS linear analysis showing concentration of elements along analyzed line (bottom graph).

Figure 8. Temperature dependences of thermal conductivity for composites with core-shell filler (left graph). Schematic representation of heat transport path along the HTC shells of the modified core-shell fillers (right image). 


\section{Figure 1.}
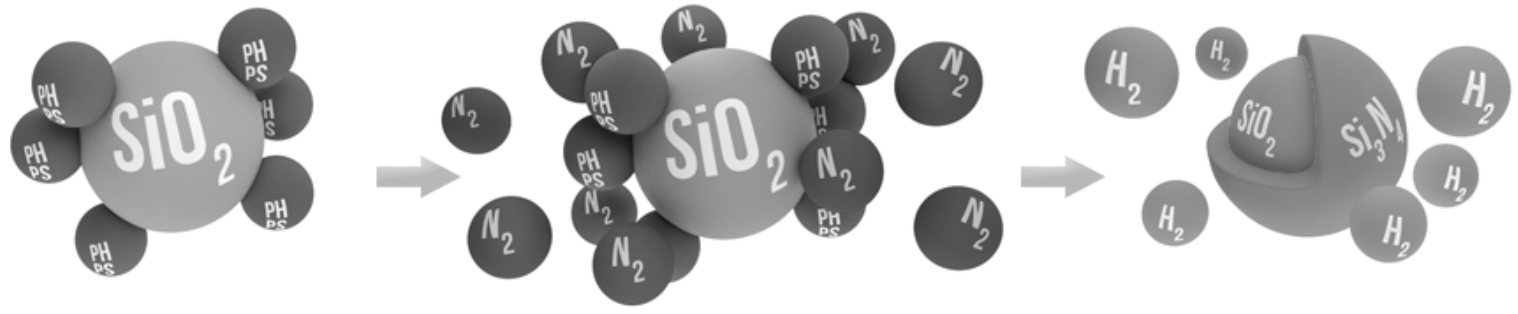

$\mathrm{SiO}_{2}$ premixed with PHPS

heated to $1000^{\circ} \mathrm{C}$ and held $2 \mathrm{~h}$ in

$\mathrm{SiO}_{2}$ covered by $\mathrm{Si}_{3} \mathrm{~N}_{4}$ layer nitrogen atmosphere
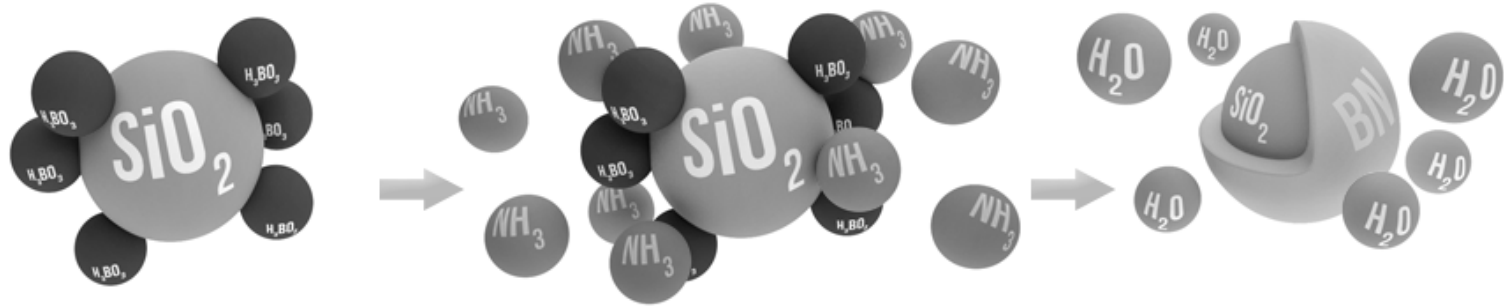

$\mathrm{SiO}_{2}$ premixed with boric acid

heated to $1000^{\circ} \mathrm{C}$ and held $2 \mathrm{~h}$ in amonia atmosphere

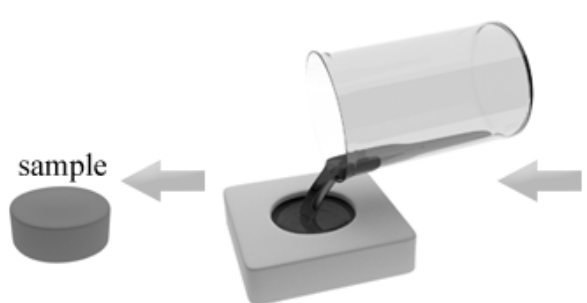

curing procedure $4 \mathrm{~h} 80^{\circ} \mathrm{C}, 8 \mathrm{~h} 140^{\circ} \mathrm{C}$

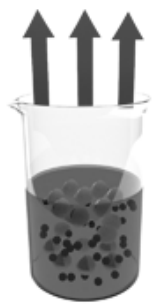

degassing

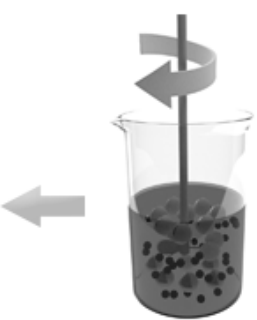

add curing agent
$\mathrm{SiO}_{2}$ covered by $\mathrm{BN}$ layer

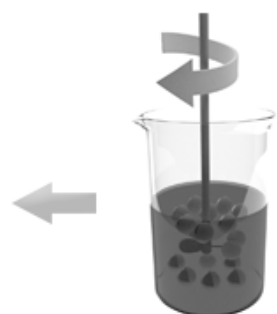

disperse in epoxy 
Figure 2.

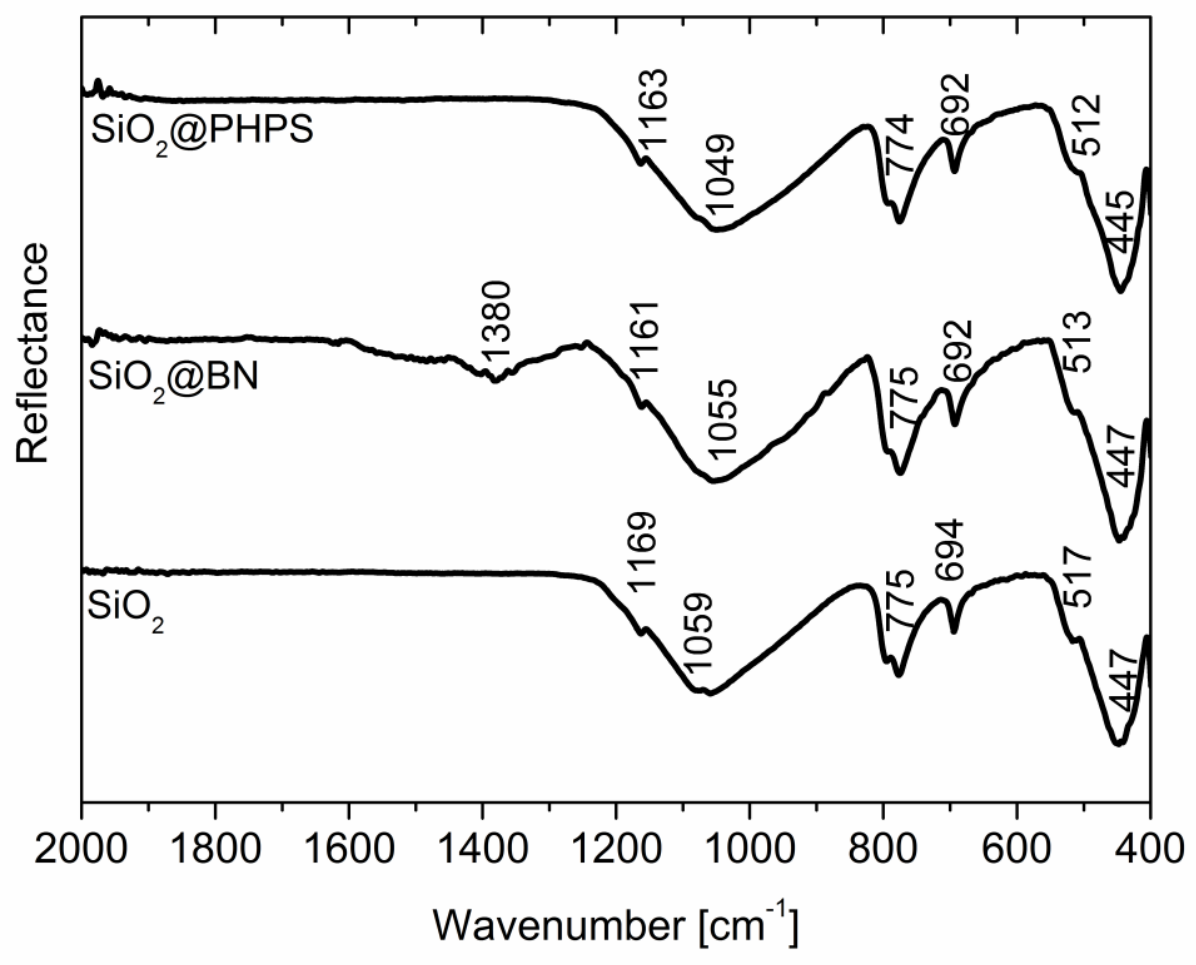


Figure 3.

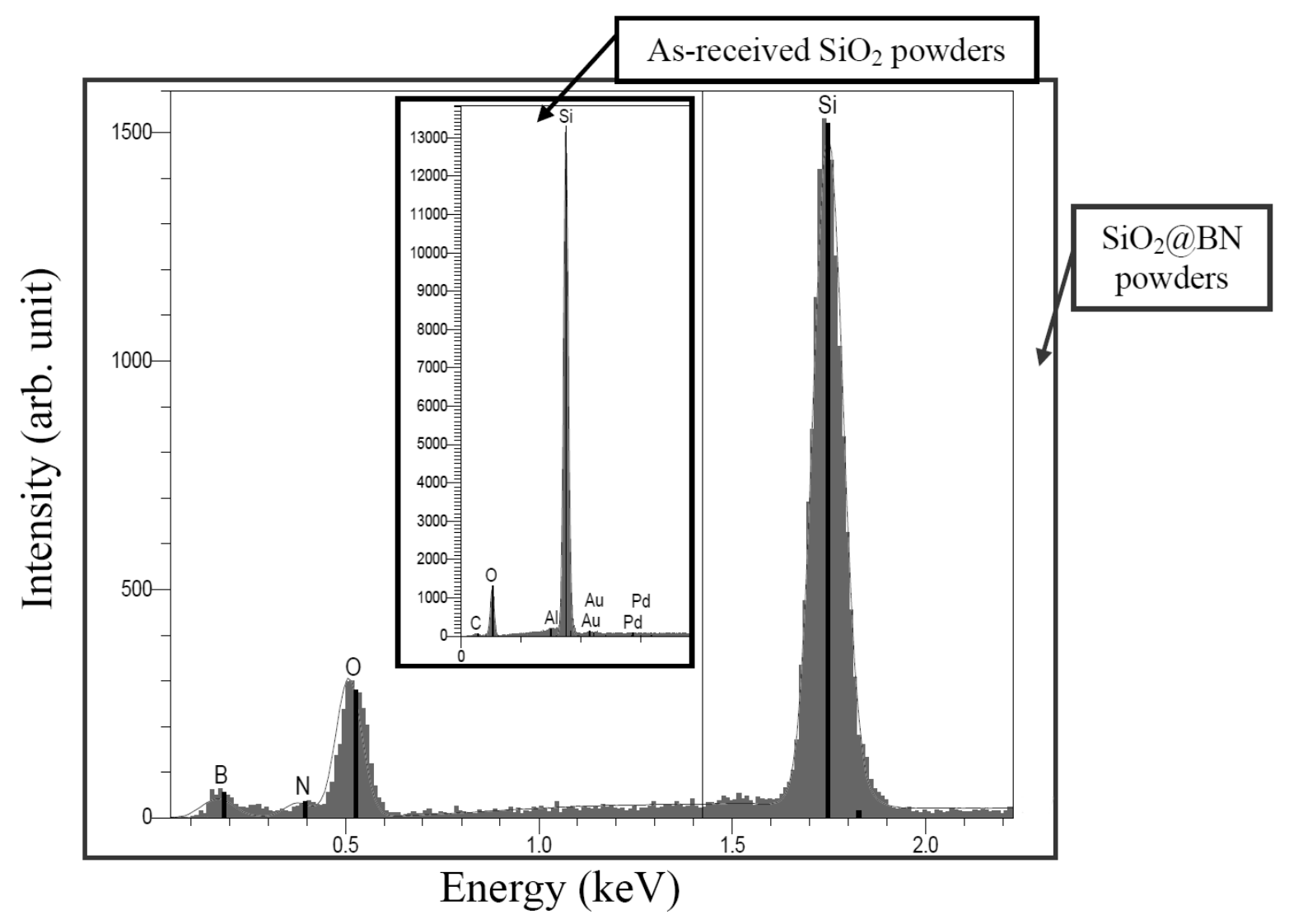


Figure 4.
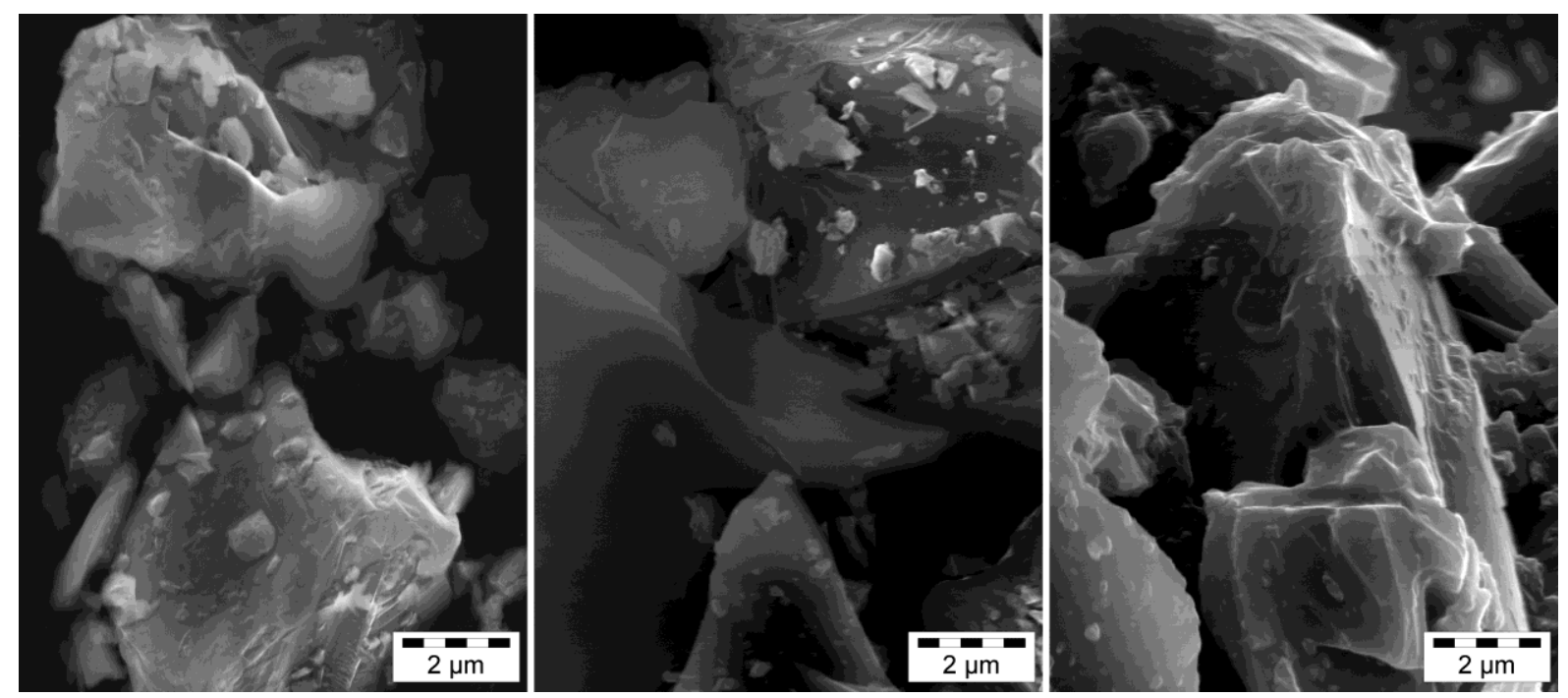
Figure 5.

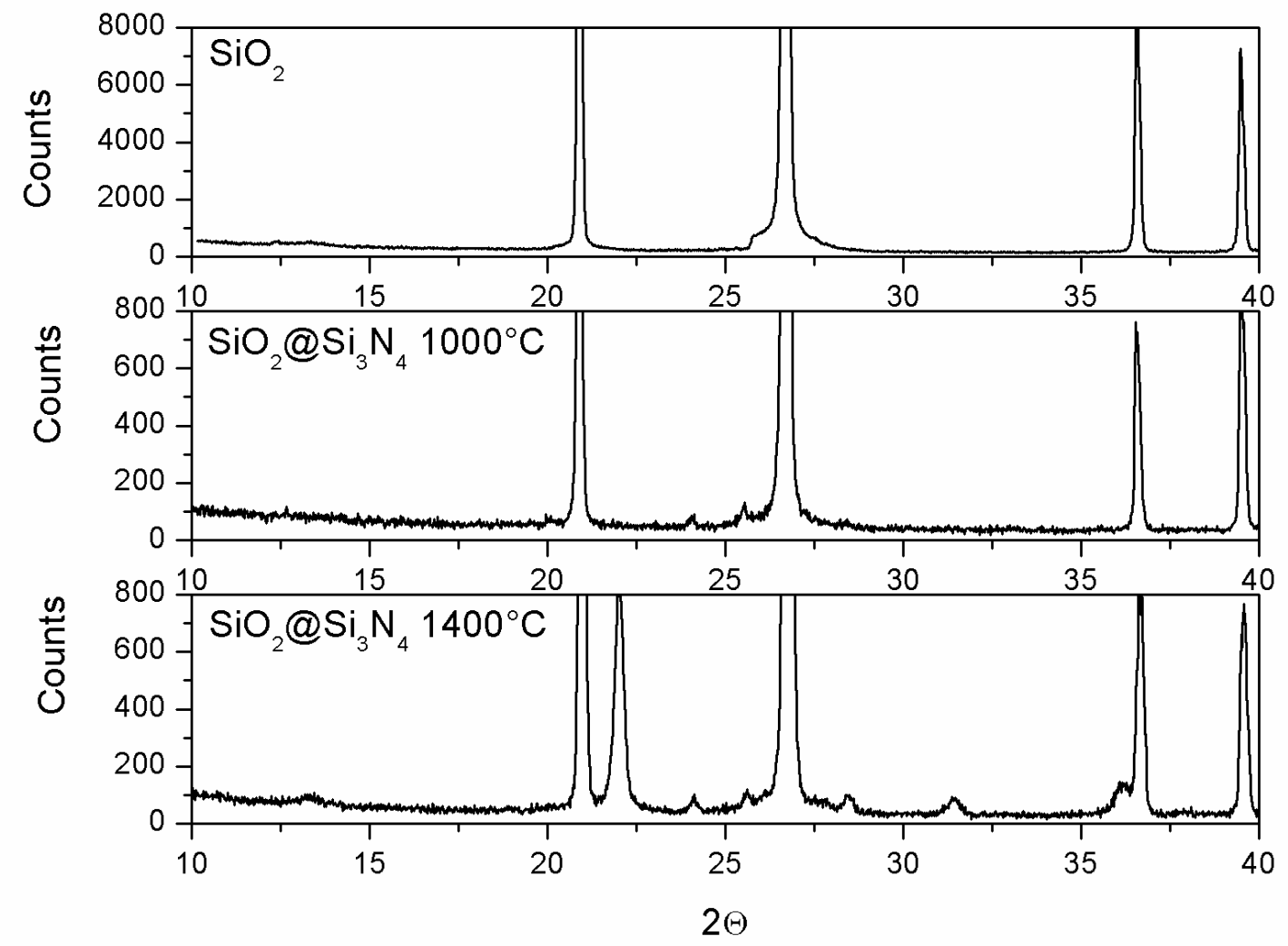


Figure 6.

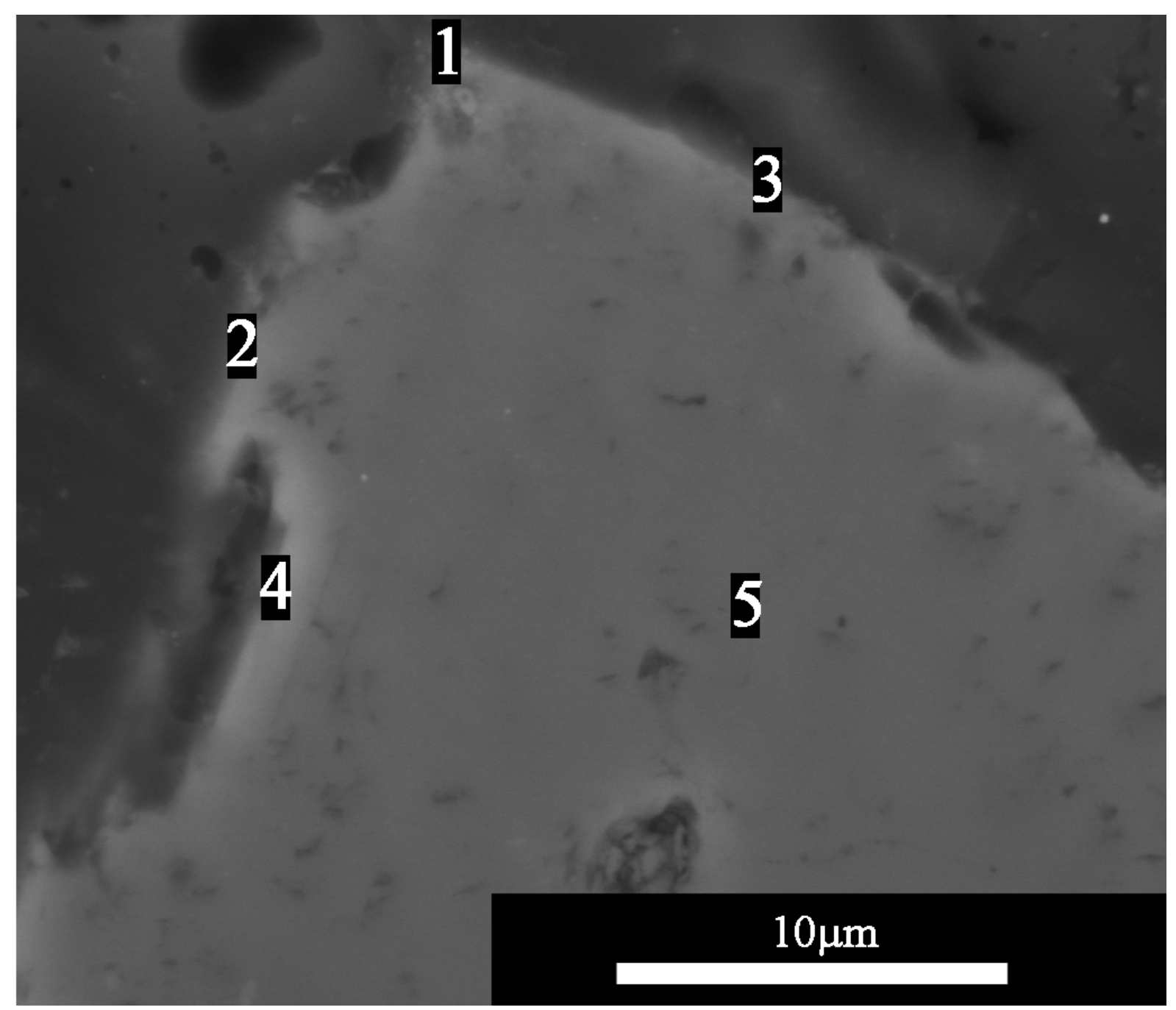


Figure 7.

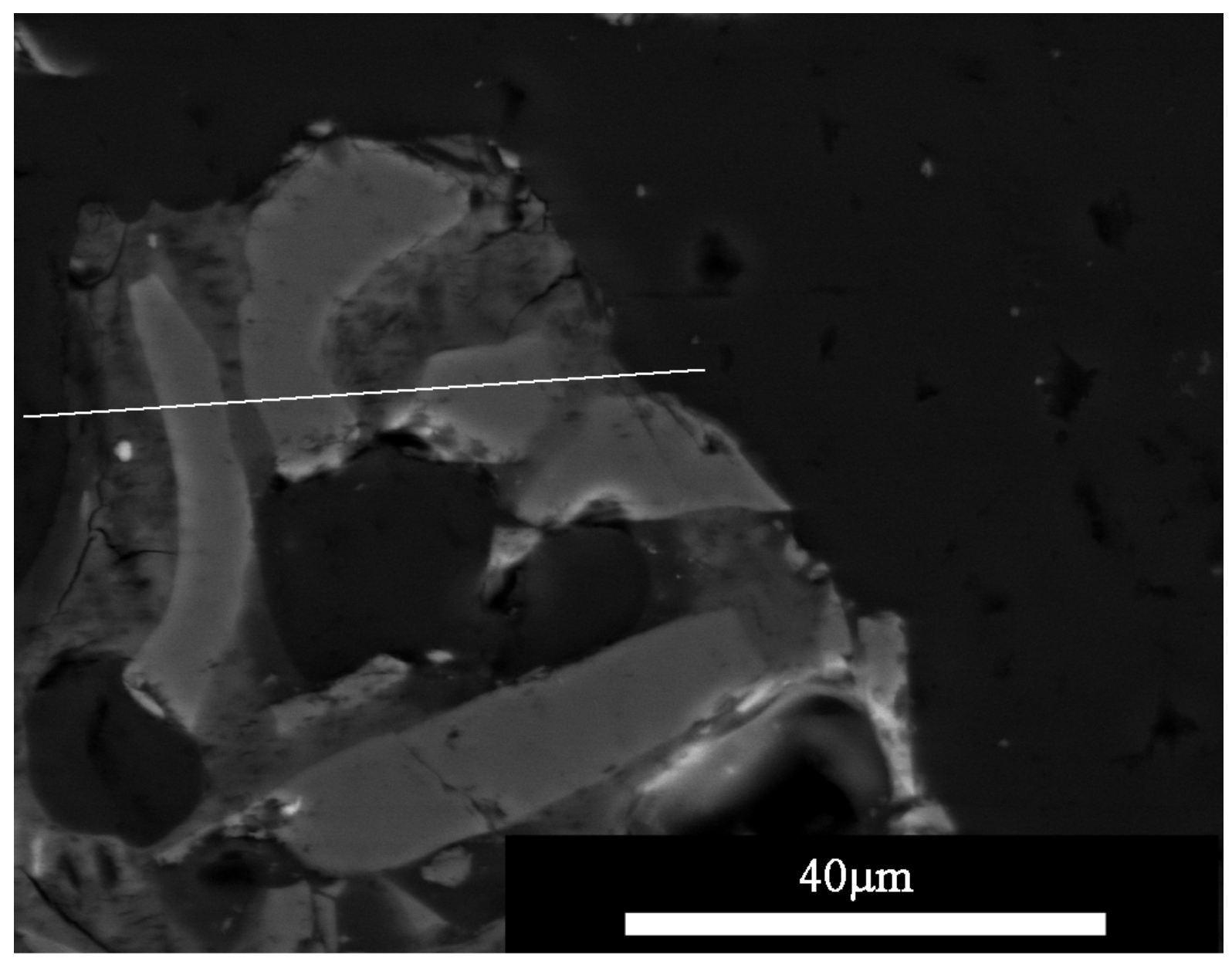

B
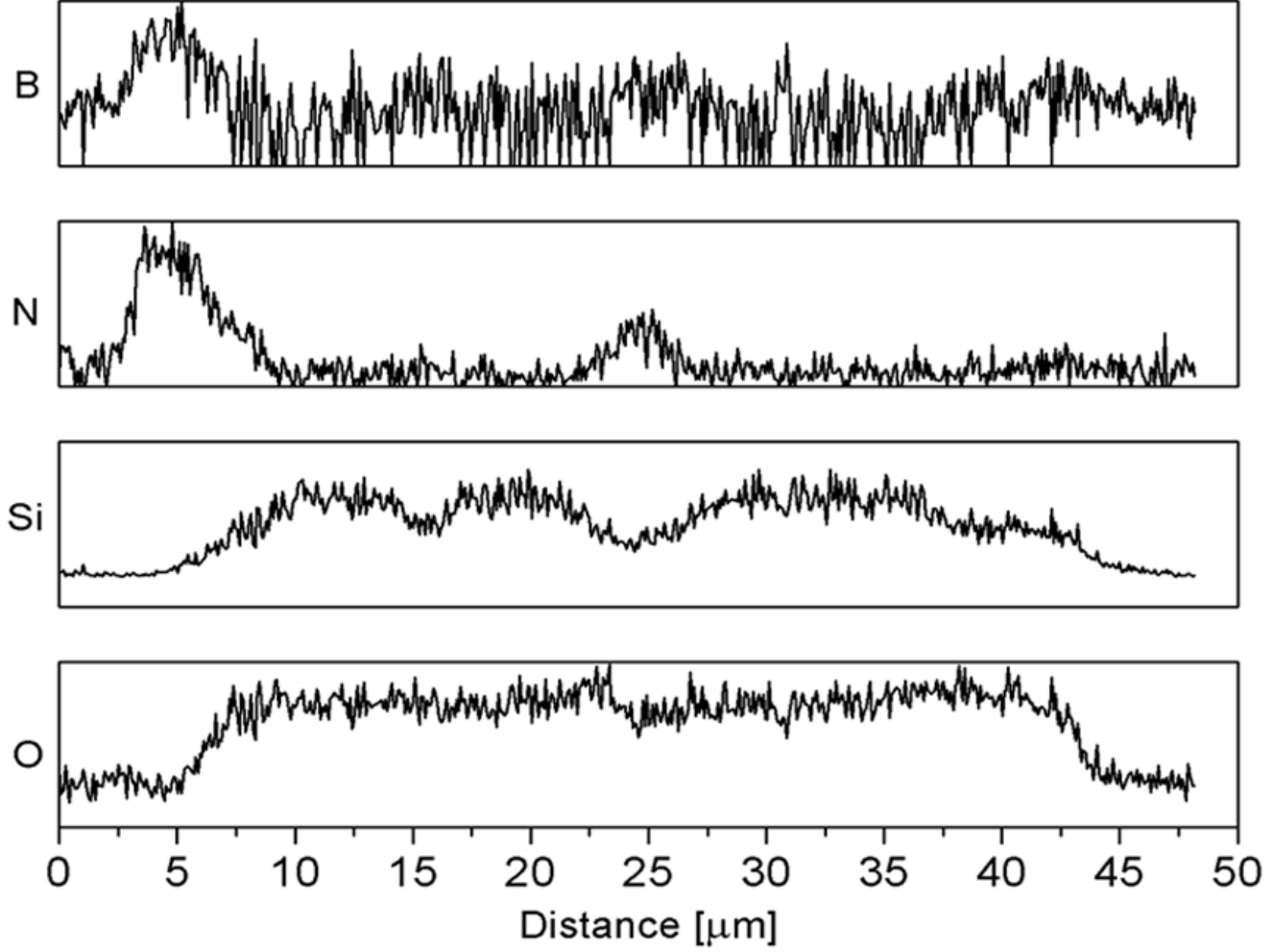
Figure 8.
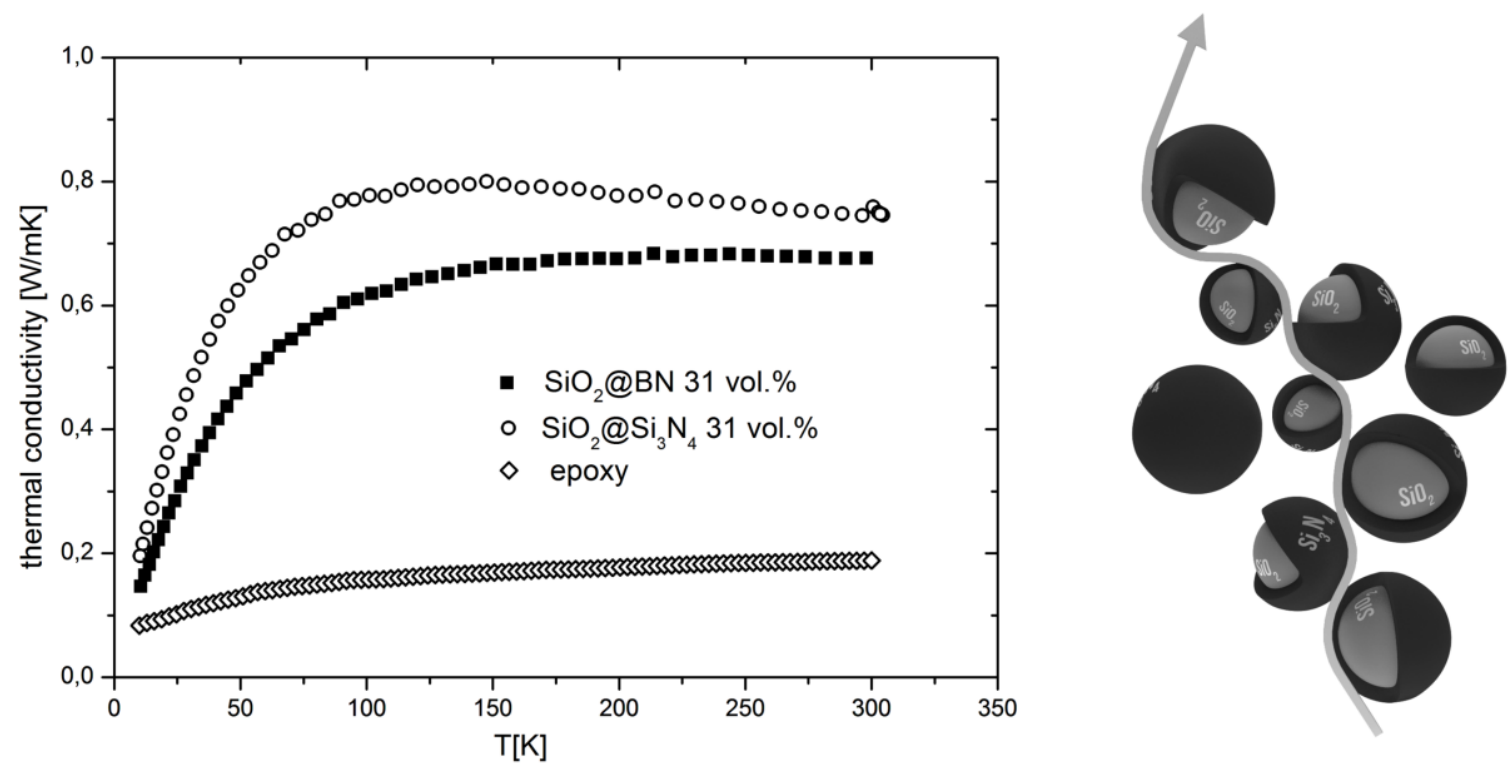